\title{
A modelling study of the latitudinal variations in the nighttime plasma temperatures of the equatorial topside ionosphere during northern winter at solar maximum
}

\author{
G. J. Bailey ${ }^{1}$, M. H. Denton ${ }^{1}$, R. A. Heelis ${ }^{2}$, S. Venkatraman ${ }^{2}$ \\ ${ }^{1}$ Department of Applied Mathematics, University of Sheffield, Sheffield S3 7RH, UK \\ 2 William B. Hanson Center for Space Sciences, University of Texas at Dallas, Richardson, Texas
}

Received: 3 May 2000 / Revised: 5 July 2000 / Accepted: 6 July 2000

\begin{abstract}
Latitudinal variations in the nighttime plasma temperatures of the equatorial topside ionosphere during northern winter at solar maximum have been examined by using values modelled by SUPIM (Sheffield University Plasmasphere Ionosphere Model) and observations made by the DMSP F10 satellite at $21.00 \mathrm{LT}$ near $800 \mathrm{~km}$ altitude. The modelled values confirm that the crests observed near $15^{\circ}$ latitude in the winter hemisphere are due to adiabatic heating and the troughs observed near the magnetic equator are due to adiabatic cooling as plasma is transported along the magnetic field lines from the summer hemisphere to the winter hemisphere. The modelled values also confirm that the interhemispheric plasma transport needed to produce the required adiabatic heating/cooling can be induced by F-region neutral winds. It is shown that the longitudinal variations in the observed troughs and crests arise mainly from the longitudinal variations in the magnetic meridional wind. At longitudes where the magnetic declination angle is positive the eastward geographic zonal wind combines with the northward (summer hemisphere to winter hemisphere) geographic meridional wind to enhance the northward magnetic meridional wind. This leads to deeper troughs and enhanced crests. At longitudes where the magnetic declination angle is negative the eastward geographic zonal wind opposes the northward geographic meridional wind and the trough depth and crest values are reduced. The characteristic features of the troughs and crests depend, in a complicated manner, on the field-aligned flow of plasma, thermal conduction, and inter-gas heat transfer. At the latitudes of the troughs/crests, the low/high plasma temperatures lead to increased/decreased plasma concentrations.
\end{abstract}

Key words: Ionosphere (equatorial ionosphere; ionosphere-atmosphere interactions)

Correspondence to: G. J. Bailey

e-mail: g.bailey@sheffield.ac.uk

\section{Introduction}

Several studies of the latitudinal variations in the nighttime plasma temperatures of the equatorial topside ionosphere have been carried out using in-situ measurements from instruments on board satellites (Hanson et al., 1973; Rishbeth et al., 1977; Heelis et al., 1978; Venkatraman and Heelis, 1999a, b) and mathematical models (Bailey et al., 1973; Bailey and Heelis, 1980; Balan et al., 1997). Hanson et al. (1973) showed that the ion and electron temperatures observed by the OGO 6 satellite are, on occasion, below the expected neutral gas temperature. On such occasions, the variation of the ion and electron temperatures along the satellite path takes the form of a trough. This phenomenon was termed 'plasma supercooling' by Hanson et al. (1973) and was observed only at night above $500 \mathrm{~km}$ altitude near the magnetic equator. It was suggested by Hanson et al. (1973) that the troughs might be due to adiabatic cooling of the plasma caused by interhemispheric transport of plasma along the magnetic field lines. This suggestion was confirmed by Bailey et al. (1973) who showed, through model calculations, that the plasma is adiabatically cooled as it flows upwards in the summer hemisphere. The model calculations also showed that the plasma is adiabatically heated as it flows downwards in the winter hemisphere. In Rishbeth et al. (1977), it was shown that the latitudinal profiles of the ion temperature observed by OGO 6 have strong longitudinal and seasonal variations and that the occurrence of ion temperature troughs is consistent with interhemispheric transport of plasma induced by neutral winds.

The Ogo 6 measurements were made during solar maximum when $F 10.7$ was about 150 and $\mathrm{O}^{+}$was usually the dominant ion at the satellite altitude. Using ion temperature and ion drift velocity measurements made by the Atmosphere Explorer D (AE-D) satellite, Heelis et al. (1978) verified the existence of interhemispheric plasma transport and ion temperature troughs in the equatorial topside ionosphere during solar minimum. The measurements were made when $F 10.7$ was 
around 75 and in regions where $\mathrm{H}^{+}$was the dominant ion. Interhemispheric plasma transport velocities between 500 and $800 \mathrm{~ms}^{-1}$ were observed. Model calculations verified that adiabatic cooling of the plasma could produce the observed ion temperature troughs. In a later modelling study (Bailey and Heelis, 1980), it was shown that the $\mathrm{O}^{+} / \mathrm{H}^{+}$transition height should represent an altitude limit above which ion cooling due to adiabatic expansion is small and that a lower altitude limit of about $600 \mathrm{~km}$ is imposed by the neutral atmosphere since it rapidly quenches any sources or sinks of heat.

More recently, Oyama et al. (1997) have presented observations made by the Japanese Hinotori satellite which show the existence of an anomaly in the latitudinal distributions of the electron temperature in the low-latitude ionosphere near $600 \mathrm{~km}$ altitude. This anomaly is called the equatorial plasma temperature anomaly (EPTA)' and is found to occur predominantly around the equinoxes and during the evening hours. The anomaly is characterized by a trough around the magnetic equator with crests on either side. The trough develops before the crests. The anomaly shows a strong dependence on solar activity and is most pronounced when the solar activity is high. The model calculations of Balan et al. (1997) show that the anomaly occurs between 19.00 and $01.00 \mathrm{LT}$ at altitudes between 450 and $1250 \mathrm{~km}$ and that the anomaly is strongest at around $21.30 \mathrm{LT}$ and $950 \mathrm{~km}$ altitude during periods of high solar activity. They also show that the trough of the anomaly arises from adiabatic cooling of the plasma and increase in plasma concentration caused by the prereversal strengthening of the upward vertical $\mathbf{E} \times \mathbf{B}$ drift. The crests arise from the combined effect of the reverse plasma fountain and nighttime plasma cooling.

The modelling study presented here has stemmed from the work of Venkatraman and Heelis (1999a), who have investigated the nighttime behaviour of the ion and electron temperatures of the equatorial topside ionosphere using observations made by the DMSP F10 satellite. Shown in Fig. 1 are averaged latitudinal variations of the ion and electron temperatures and total ion concentration observed at 21.00 LT near $800 \mathrm{~km}$ altitude in the longitude regions $0^{\circ}-40^{\circ}, 180^{\circ}-210^{\circ}$, and $300^{\circ}-$ $340^{\circ}$. The observations were made during January 1991 when $F 10.7$ was around 220 . The vertical lines on the plots denote the standard deviations of the observations. The standard deviations of the ion temperatures, $T_{i}$, are similar to those of the electron temperatures, $T_{e}$, and are not included in the figure. The temperature profiles show a trough centred slightly to the south of the magnetic equator (summer hemisphere) and by a crest near $15^{\circ}$ latitude in the winter hemisphere. The plasma temperatures of the trough do not lie below the expected neutral gas temperature (see Hanson et al., 1973). The crests in the ion temperature are more pronounced than those in the electron temperature. The troughs and crests are most prominent in the longitude region $180^{\circ}-210^{\circ}$, where the magnetic declination angle is near $10^{\circ}$, and almost absent in the longitude region $300^{\circ}-340^{\circ}$, where the magnetic declination angle is near $-18^{\circ}$. In the longitude region $0^{\circ}-40^{\circ}$, the magnetic declination angle is close to zero. Venkatraman and Heelis (1999a) have attributed the longitudinal variations in the latitudinal variations of the plasma temperatures to the roles played by the geographic meridional and zonal winds in modulating the interhemispheric plasma transport and the peak heights of the F-regions in the summer and winter hemispheres. The latitudinal variations of the plasma temperatures have also been shown to be strongly dependent on the $\mathrm{O}^{+} / \mathrm{H}^{+}$transition height and on the level of solar activity (Venkatraman and Heelis, 1999b). The troughs and crests have their greatest values during solar maximum. As pointed out by Venkatraman and Heelis (1999a), there is insufficient information in the observed data to determine the extent of the adiabatic cooling. Figure 1 also shows significant differences in the latitudinal variations in the total ion concentration. Within the longitude region $300^{\circ}-340^{\circ}$, the total ion concentration is almost symmetric about the magnetic equator.

In this work, the longitudinal variations of the troughs and crests that occur in the plasma temperature profiles displayed in Fig. 1 are investigated through model calculations. The cooling/heating of the plasma by adiabatic expansion/compression will be determined. Also investigated are the effects of adiabatic cooling/ heating on the plasma concentrations.

\section{Mathematical model}

The model used is SUPIM, the Sheffield University Plasmasphere-Ionosphere Model (Bailey and Sellek, 1990; Bailey et al., 1993; Bailey and Balan, 1996). In SUPIM, coupled time-dependent equations of continuity, momentum, and energy for the $\mathrm{O}^{+}, \mathrm{H}^{+}, \mathrm{He}^{+}, \mathrm{N}_{2}^{+}$, $\mathrm{O}_{2}^{+}$, and $\mathrm{NO}^{+}$ions, and the electrons, are solved along closed magnetic field lines for the ion and electron concentrations, field-aligned velocities, and temperatures. For expediency, the geomagnetic field is represented by an axial centred-dipole. The magnetic declination angle is taken into account in the model calculations through the magnetic meridional wind, which is dependent on the geographic meridional and zonal winds and the magnetic declination angle (see Eq. 6). The geographic meridional and zonal wind velocities are based on those given by HWM90 (Hedin et al., 1991). The concentrations and temperatures of the neutral gases are given by the MSIS86 thermospheric model (Hedin, 1987). The solar EUV fluxes are given by the EUVAC solar EUV flux model (Richards et al., 1994). The vertical $\mathbf{E} \times \mathbf{B}$ plasma drift velocity is taken either to be zero or to be given by the recently published global empirical model of Scherliess and Fejer (1999). In this model, the equatorial vertical $\mathbf{E} \times \mathbf{B}$ plasma drift velocities are determined from combined incoherent scatter radar observations made at Jicamarca and ion drift meter observations made by the AE-E satellite. The zonal $\mathbf{E} \times \mathbf{B}$ plasma drift velocity is taken to be zero.

The energy equation for the $i$ th constituent ( $i=\mathrm{O}^{+}, \mathrm{H}^{+}, \mathrm{H}^{+}, e$, where $e$ denotes electrons) is 

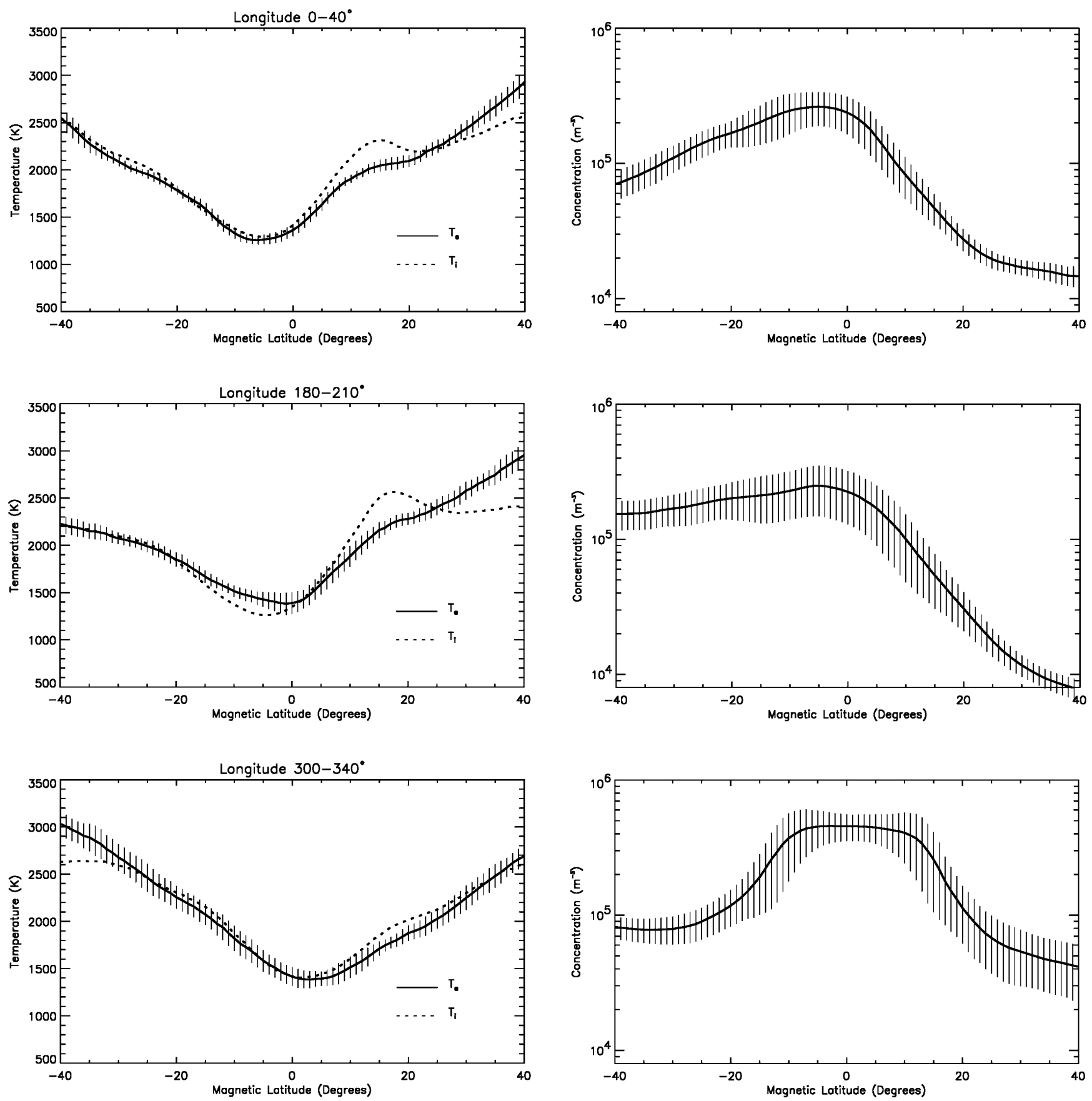

Fig. 1. Averaged latitudinal profiles of the ion and electron temperature and total ion concentration observed by the DMSP F10 satellite at $800 \mathrm{~km}$ altitude and $21.00 \mathrm{LT}$ during January 1991 in the longitude regions $0^{\circ}-40^{\circ}, 180^{\circ}-210^{\circ}$, and $300^{\circ}-340^{\circ}$. The vertical lines on the

plots denote the standard deviations of the observations. The standard deviations of the ion temperatures, $T_{i}$, are similar to those of the electron temperatures, $T_{e}$, and are not displayed

$\frac{3}{2} k N_{i}\left(\frac{\partial T_{i}}{\partial t}+\mathbf{v}_{i} \cdot \operatorname{grad} T_{i}\right)=Q_{i}-p_{i} \operatorname{div} \mathbf{v}_{i}$

$$
+\operatorname{div}\left(\kappa_{i} \operatorname{grad} T_{i}\right)
$$

where

$k=$ Boltzmann's constant,

$N_{i}=$ concentration,

$T_{i}=$ temperature,

$\mathbf{v}_{i}=\mathbf{v}_{i}^{\prime \prime}+\mathbf{v}^{\perp}$,

$\mathbf{v}_{i}^{\prime \prime}=$ field-aligned velocity,

$\mathbf{v}^{\perp}=$ vertical $\mathbf{E} \times \mathbf{B}$ plasma drift velocity,

$Q_{i}=$ heating rate,

$p_{i}=$ pressure $\left(=k N_{i} T_{i}\right)$,

$\kappa_{i}=$ thermal conductivity

The temperature of the molecular ions is taken to be that of the $\mathrm{O}^{+}$ion.

The thermal conductivities of the $i$ th ion constituent and the electrons, $\kappa_{i}$ and $\kappa_{e}\left(\mathrm{eV} \mathrm{cm}^{-1} \mathrm{~s}^{-1} \mathrm{~K}^{-1}\right)$, respectively, are evaluated from the expressions 
$\kappa_{i}=\frac{4.6 \times 10^{4} N_{i}}{A_{i}^{0.5} N_{e}} T_{i}^{2.5}$

where $A_{i}$ is the ion mass in a.m.u., and

$$
\kappa_{e}=\frac{7.7 \times 10^{5} T_{e}^{2.5}}{\left[1+\frac{3.22 \times 10^{4} T_{e}^{2}}{N_{e}}\left[q(O) n(O)+q\left(N_{2}\right) n\left(N_{2}\right)+q\left(O_{2}\right) n\left(O_{2}\right)\right]\right]}
$$

where

$$
\begin{aligned}
& q(O)=1.1 \times 10^{-16}\left(1+5.7 \times 10^{-4} T_{e}\right) \\
& q\left(N_{2}\right)=2.82 \times 10^{-17} T_{e}^{0.5}\left(1-1.21 \times 10^{-4} T_{e}\right) \\
& q\left(O_{2}\right)=2.2 \times 10^{-16}\left(1+3.6 \times 10^{-2} T_{e}^{0.5}\right)
\end{aligned}
$$

The heating rates $Q_{i}\left(i=\mathrm{O}^{+}, \mathrm{H}^{+}, \mathrm{H} e^{+}\right)$are given by

$Q_{i}=Q_{i e}+\sum_{j \neq i} Q_{i j}+Q_{i n}$

and the heating rate $Q_{e}$ by

$Q_{e}=Q_{p h . e}+\sum_{j} Q_{e j}+Q_{e n}$

where $\sum_{j}$ denotes summation over the ions and $\sum_{j \neq i}$ denotes summation over the ions except for the $i$ th. The terms $Q_{i e}, Q_{i j}$, and $Q_{i n}$ denote the heating rates between the $i$ th ion and the electrons, $j$ th ion, and neutral gases, respectively. The term $Q_{e j}$ denotes the heating rate between the electrons and $j$ th ion and $Q_{e n}$ between the electrons and neutral gases. Expressions for these terms are given in Bailey and Sellek (1990) and Bailey and Balan (1996).

The term $Q_{\text {ph.e }}$ denotes the heating rate by the photoelectrons. It is calculated by the method developed by Richards and co-workers (Richards and Torr, 1988). In this method, energetic photoelectrons are produced by photoionization of the neutral gases. These photoelectrons heat the thermal electrons through Coulomb collisions, magnetic trapping due to pitch angle diffusion, and backscattering from the conjugate hemisphere. However, there is insufficient heat produced by these processes to give the observed ion and electron temperatures at the higher latitudes. Thus, to obtain agreement in the modelled and observed values we have followed previous workers (Chandler et al., 1987; Balan et al., 1996, 1997) and introduced an equatorial high-altitude heat source. Such a heat source might arise from interactions between the electrons in the radiation belts and thermal electrons in the equatorial plasmasphere (Bühler, 1998). The heat source is applied as energy input along the magnetic field lines with apex altitude greater than $600 \mathrm{~km}$ between $\pm 10^{\circ}$ latitude. The plasma temperature at high altitudes and its latitudinal variation are little affected by the width of the heating region. They are, however, affected by the total energy input. For the present study, the heat source has energy rate $4 \times 10^{6} \mathrm{eV} \mathrm{m}^{-3} \mathrm{~s}^{-1}$ during the day and $0.5 \times 10^{6}$ $\mathrm{eV} \mathrm{m}^{-3} \mathrm{~s}^{-1}$ during the night; linear interpolation between these values is used during the sunrise and sunset periods. This heat source increases the daytime total energy input between latitudes $\pm 10^{\circ}$, along field lines with apex altitude greater than $1000 \mathrm{~km}$, by about $5 \%$. Without this additional heat source the model calculations give plasma temperatures that are about $800 \mathrm{~K}$ lower than observed at latitudes around $\pm 40^{\circ}$ (figure not shown); with increasing latitude the differences become much greater. Within the trough region, the modelled temperatures are similar to those observed.

\section{Model calculations and results}

The model calculations have been carried out along magnetic field lines with apex altitude distributed between 150 and $9000 \mathrm{~km}$. The intervals in apex altitude vary from $25 \mathrm{~km}$ (for field lines with apex altitude less than $400 \mathrm{~km}$ ) to $1000 \mathrm{~km}$ (for field lines with apex altitude greater than $6000 \mathrm{~km}$ ). For each set of model calculations, $F 10.7=220, A p=4$, and the day number is 16. These model inputs are appropriate for the atmospheric conditions occurring during January 1991 when the observations used in this study were made.

As described in the Introduction, the troughs/crests that occur in the latitudinal variations of the plasma temperatures arise from adiabatic cooling/heating of the plasma caused by interhemispheric plasma transport. Interhemispheric plasma transport arises from an imbalance in plasma pressure along the magnetic field lines. During the solstices this imbalance is caused, principally, by asymmetries in the magnetic meridional wind (component of neutral wind in the magnetic meridian) in the $\mathrm{F}$ regions of the summer and winter hemispheres. Such winds can be as large as $300 \mathrm{~ms}^{-1}$ (Blum and Harris, 1975). Bailey and Heelis (1980) have shown that winds of $100 \mathrm{~ms}^{-1}$ can induce interhemispheric ion field-aligned velocities of $300 \mathrm{~ms}^{-1}$ along field lines with apex altitude around $1000 \mathrm{~km}$. The neutral wind has little altitude variation above about $300 \mathrm{~km}$ altitude due to the effects of viscosity (Rishbeth, 1972).

The magnetic meridional wind velocity, $U$ (positive in the southward direction), is related to the geographic meridional wind velocity, $U_{\theta}$ (positive in the southward direction), and geographic zonal wind velocity, $U_{\phi}$ (positive in the eastward direction), through the relationship

$U=U_{\theta} \cos D-U_{\phi} \sin D$

where $D$ is the magnetic declination angle (positive in the eastwards direction). Usually, the longitudinal variation in the magnetic meridional wind arising from the longitudinal variations in the geographic meridional and zonal winds is small when compared to the longitudinal variation arising from the longitudinal variation in the magnetic declination angle.

Figure 2 shows latitudinal variations of the magnetic meridional wind velocity at $300 \mathrm{~km}$ altitude and 21.00 LT for magnetic declination angles $0^{\circ}, 15^{\circ}$, and $-15^{\circ}$. These values are representative of the global variation in the magnetic declination angle and of the respective longitude regions $0^{\circ}-40^{\circ}, 180^{\circ}-210^{\circ}$, and $300^{\circ}-340^{\circ}$, the 


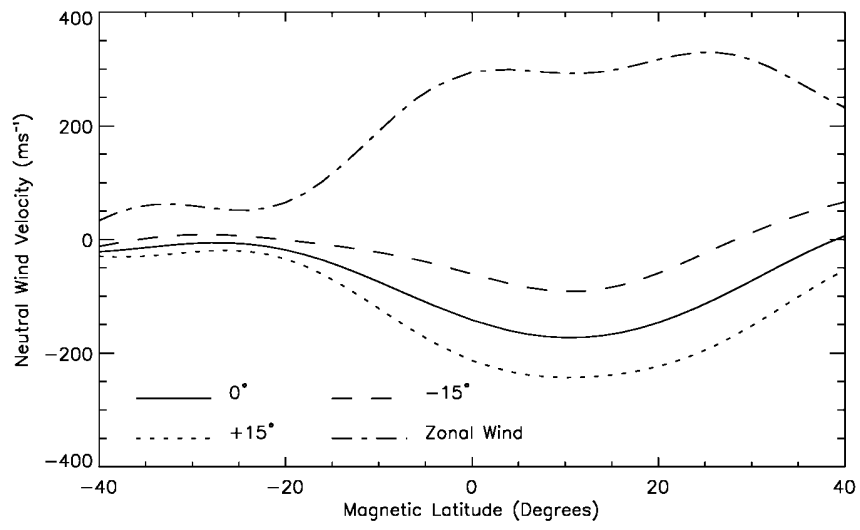

Fig. 2. Latitudinal profiles at $300 \mathrm{~km}$ altitude and $21.00 \mathrm{LT}$ of the magnetic meridional wind velocity for magnetic declination angles $0^{\circ}$, $15^{\circ}$, and $-15^{\circ}$, and of the geographic zonal wind velocity. These values are representative of the respective longitude regions $0^{\circ}-40^{\circ}$, $180^{\circ}-210^{\circ}$, and $300^{\circ}-340^{\circ}$

binning intervals used in the construction of Fig. 1. For each wind pattern, the geographic meridional and zonal winds given by HWM90 (Hedin et al., 1991) have been modified (at all times) by increasing their magnitudes by the factor 2 and, for the geographic meridional wind, by moving its latitude profile through $20^{\circ}$ in the summerto-winter hemisphere direction. The latitudinal variation of the geographic zonal wind velocity at $300 \mathrm{~km}$ altitude and 21.00 LT is also shown in Fig. 2 (dot-dash curve); the geographic meridional wind is given by solid curve of Fig. 2 (magnetic meridional wind with zero magnetic declination angle). These modifications have been carried out to improve the agreement in the modelled and observed latitudinal profiles for the ion and electron temperatures and electron (total ion) concentration. Other authors, e.g. Su et al. (1995), have also found it necessary to modify the magnitude and phase of the meridional winds given by HWM90 for the low-latitude region in order to obtain agreement in their modelled and observed values of plasma concentration and temperature. Stening (1992) has pointed out that there are considerable uncertainties in the values given by HWM90 for the neutral winds at low latitudes. These uncertainties are due, principally, to the data coverage of the HWM90 model being sparse in the low-latitude region. A comparison of the profiles displayed in Fig. 2 shows that a combination of an eastward geographic zonal wind and a positive magnetic declination angle increases the magnitude of the magnetic meridional wind velocity while a combination of an eastward zonal wind and a negative magnetic declination angle decreases the magnitude of the magnetic meridional wind velocity.

Shown in Fig. 3 are the latitudinal variations of the $\mathrm{O}^{+}$and electron temperatures, and electron concentration, at $800 \mathrm{~km}$ altitude and $21.00 \mathrm{LT}$ obtained from model calculations in which the magnetic declination angle is $0^{\circ}$ (left-hand column), $15^{\circ}$ (centre column), and $-15^{\circ}$ (right-hand column). For each magnetic declination angle, two sets of model calculations have been carried out. In the set A calculations the $p \operatorname{div} \mathbf{v}$ term has been included in the ion and electron energy equations while in the set B calculations it has been excluded. It should be noted that the cooling/heating arising from this term is due to field-aligned plasma transport adiabatically expanding the plasma on the upwind side of the magnetic equator and adiabatically compressing the plasma on the downwind side. For the modelled values considered here, the $\mathrm{H}^{+}$and $\mathrm{He}^{+}$temperatures lie between the $\mathrm{O}^{+}$and electron temperatures (figure not shown).

The values shown in Fig. 3 for magnetic declination angles $0^{\circ}$ and $15^{\circ}$ (left-hand and centre columns) have been obtained from model calculations in which the $\mathbf{E} \times \mathbf{B}$ plasma drift velocity is taken to be zero while those shown for magnetic declination angle $-15^{\circ}$ (righthand column) have been obtained from model calculations in which the $\mathbf{E} \times \mathbf{B}$ plasma drift velocity has been obtained from the global empirical model of Scherliess and Fejer (1999). The local time variation of the equatorial vertical $\mathbf{E} \times \mathbf{B}$ plasma drift velocity, which is taken to be independent of altitude, is displayed in Fig. 4. In Su et al. (1995), it has been shown that an altitude variation in the equatorial vertical $\mathbf{E} \times \mathbf{B}$ plasma drift velocity can affect the latitudinal and diurnal variations of the plasma temperatures and concentrations in the equatorial topside ionosphere. However, the altitude variation is unknown and, since its inclusion will not affect the conclusions of the present study, it has not been included in the model calculations. The latitudinal variation of the $\mathbf{E} \times \mathbf{B}$ drift velocity is in accord with the dipole field-line geometry (Bailey and Sellek, 1990). The calculated total ion concentrations obtained for magnetic declination angles $0^{\circ}$ and $15^{\circ}$ (left-hand and centre columns) are in closer agreement with the observed values than those obtained from calculations that include the $\mathbf{E} \times \mathbf{B}$ plasma drift. This unexpected result is probably a consequence of using an $\mathbf{E} \times \mathbf{B}$ plasma drift inconsistent with the observations. It should be remembered that the Scherliess and Fejer (1999) model is based on incoherent scatter radar observations made at Jicamarca and by observations made by the ion drift meter on board the AE-E satellite. The observed equatorial vertical $\mathbf{E} \times \mathbf{B}$ plasma drift velocities have considerable longitudinal variation, especially at solar maximum (Scherliess and Fejer, 1999). As discussed later, the latitudinal variation of the modelled plasma temperatures at $800 \mathrm{~km}$ altitude and $21.00 \mathrm{LT}$ are little affected by the $\mathbf{E} \times \mathbf{B}$ plasma drift. The $\mathbf{E} \times \mathbf{B}$ plasma drift does, however, lead to significant differences in the electron concentration profiles (see Fig. 5).

A comparison of the temperature profiles obtained from the set A and set B calculations clearly shows that the $p \operatorname{div} \mathbf{v}$ term in the energy equation acts as a heat source in the winter hemisphere, leading to crests in both the $\mathrm{O}^{+}$and electron temperatures at latitudes near $15^{\circ}$, and a heat sink in the summer hemisphere, leading to troughs in the $\mathrm{O}^{+}$and electron temperatures centred at latitudes near $5^{\circ}$ in the summer hemisphere. The crests in the $\mathrm{O}^{+}$temperature are much greater than those in the electron temperature due to the dominant role 

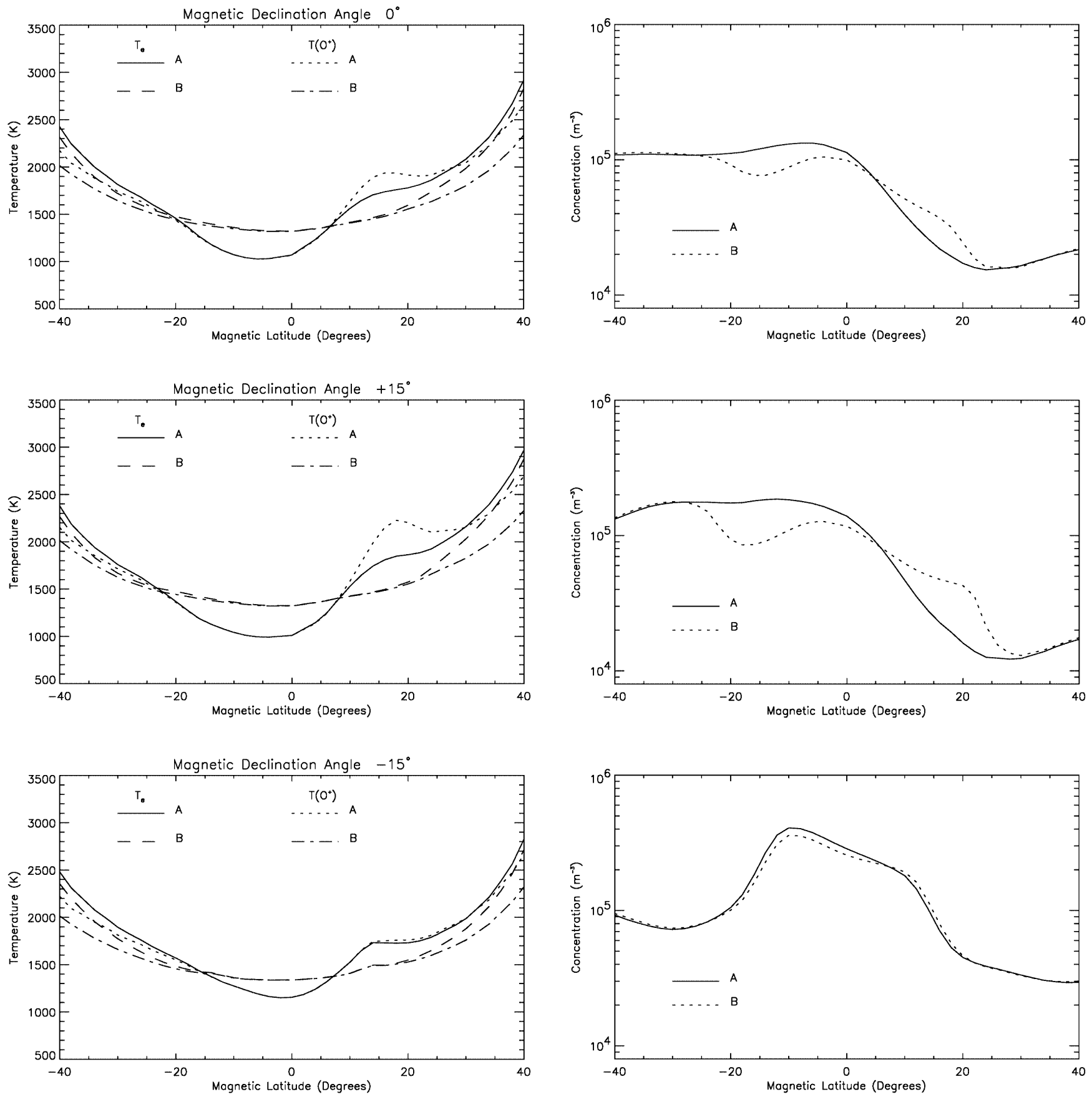

Fig. 3. Latitudinal profiles at $800 \mathrm{~km}$ altitude and $21.00 \mathrm{LT}$ of the modelled $\mathrm{O}^{+}$and electron temperatures, and electron concentration, for magnetic declination angles $0^{\circ}, 15^{\circ}$, and $-15^{\circ}$. The curves labelled $A$ have been obtained from calculations which include the $p \operatorname{div} \mathbf{v}$ term in the ion and electron energy equations. The curves labelled $B$ have been obtained from calculations that exclude the term. The curves displayed for magnetic declination angles $0^{\circ}$ and $15^{\circ}$ (left-hand and

centre columns) have been obtained from model calculations in which the $\mathbf{E} \times \mathbf{B}$ plasma drift velocity is taken to be zero while those shown for magnetic declination angle $-15^{\circ}$ (right-hand column) have been obtained from model calculations in which the $\mathbf{E} \times \mathbf{B}$ plasma drift velocity has been obtained from the global empirical model of Scherliess and Fejer (1999) (see Fig. 4)

played by thermal conduction in the electron gas; the thermal conductivity of the ion gas is almost negligible. In the trough region, the $\mathrm{O}^{+}$and electron temperatures have similar values due to the strong thermal coupling between the $\mathrm{O}^{+}$and electron gases arising from the high plasma concentrations. The results obtained from the model calculations that include the $p \operatorname{div} \mathbf{v}$ term in the

ion and electron energy equations (set A calculations) are in qualitative agreement with the observed values; the modelled values are generally lower than the observed values. No attempt has been made to obtain quantitative agreement in the modelled and observed values since the purpose of the present study is to determine the effects of adiabatic cooling/heating on the 


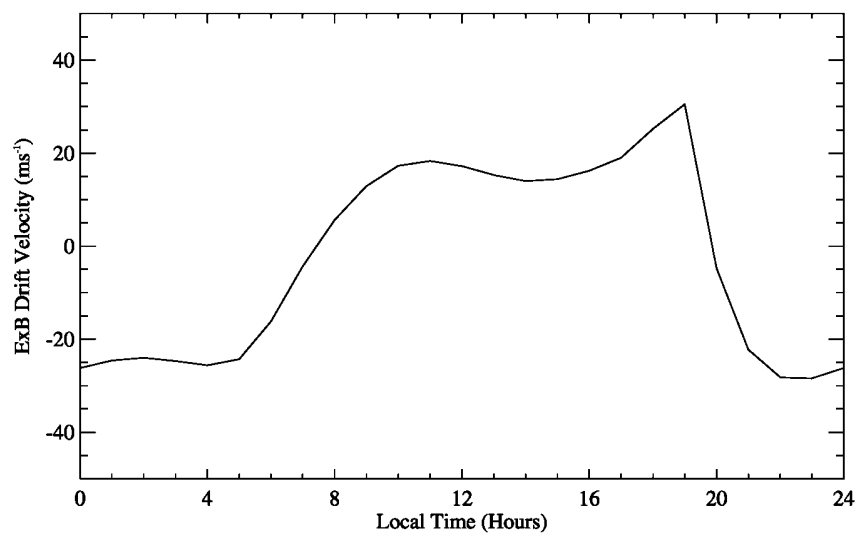

Fig. 4. Local time variation of the equatorial vertical $\mathbf{E} \times \mathbf{B}$ plasma drift velocity
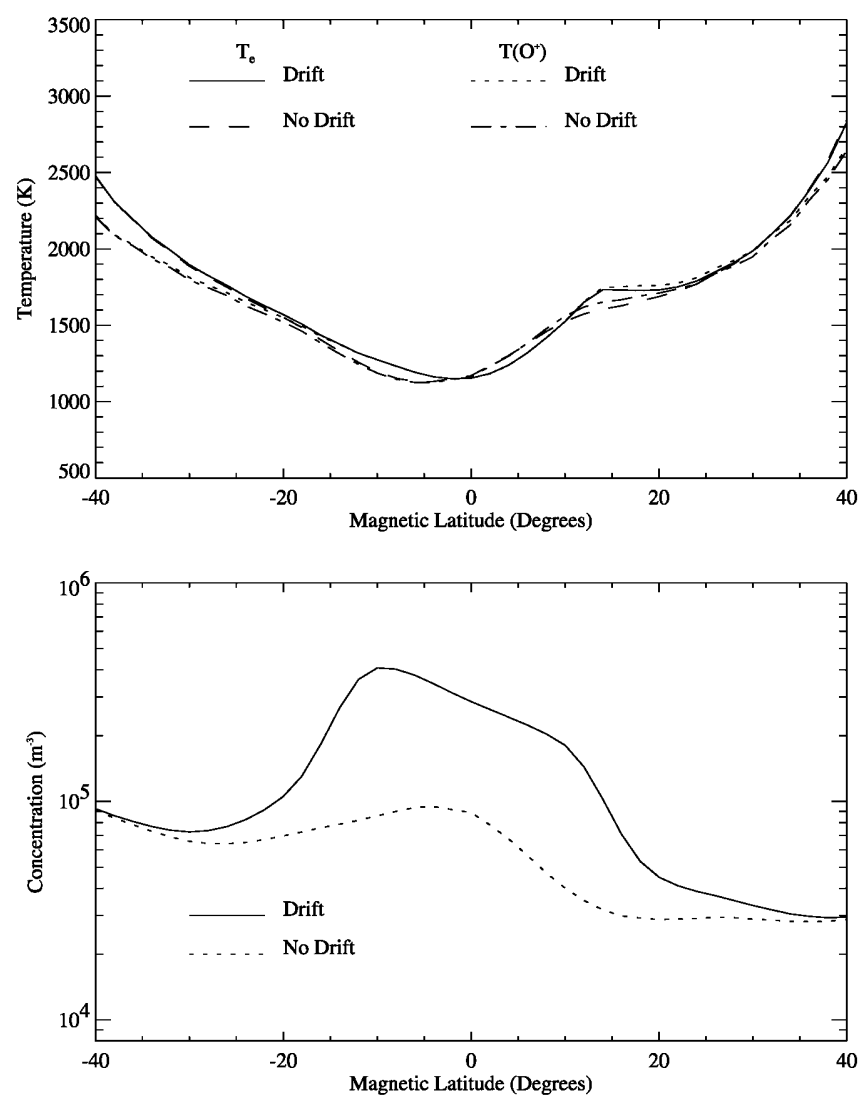

Fig. 5. Latitudinal profiles at $800 \mathrm{~km}$ altitude and $21.00 \mathrm{LT}$ of the modelled $\mathrm{O}^{+}$and electron temperatures, and electron concentration, obtained from calculations set $\mathrm{A}$ with magnetic declination angle $-15^{\circ}$ which include and exclude the vertical $\mathbf{E} \times \mathbf{B}$ plasma drift velocity

characteristic features of the latitudinal profiles. A further comparison of Figs. 1 and 3 shows that the modelled electron concentrations are also in close agreement with the observed total ion concentrations when adiabatic cooling/heating is included in the model calculations.

The increase in magnitude of the magnetic meridional wind velocity due to using a magnetic declination angle of $15^{\circ}$ rather than $0^{\circ}$ (see Fig. 2) leads to significantly increased values in the modelled $\mathrm{O}^{+}$field-aligned velocities in the winter hemisphere (figure not shown) which, in turn, leads to increased crest values in the $\mathrm{O}^{+}$ temperature. Although there are similar increases in the electron field-aligned velocity, there is only a small increase in the crest value of the electron temperature due to the high thermal conductivity of the electron gas. The increase in the magnetic meridional wind in the summer hemisphere is much smaller than that in the winter hemisphere. This increase is insufficient to induce the significant increases in the $\mathrm{O}^{+}$and electron fieldaligned velocities in the trough region that are needed to make significant changes to the depths of the $\mathrm{O}^{+}$and electron temperature troughs. The increase in the magnetic meridional wind velocity also leads to increases in the total ion concentration at $21.00 \mathrm{LT}$ and $800 \mathrm{~km}$ altitude in the summer hemisphere and decreases in the winter hemisphere. These changes arise because the greater summer-to-winter hemisphere magnetic meridional wind velocity raises the $\mathrm{F}$ region in the summer hemisphere to altitudes of lower chemical loss and lowers the $\mathrm{F}$ region in the winter hemisphere to altitudes of greater chemical loss.

As expected, the decrease in magnitude of the magnetic meridional wind velocity due to using a magnetic declination angle of $-15^{\circ}$ rather than $0^{\circ}$ (see Fig. 2) leads to significantly decreased values in the modelled $\mathrm{O}^{+}$and electron field-aligned velocities (figure not shown) which, in turn, leads to decreased trough depths and crest values in the $\mathrm{O}^{+}$and electron temperatures. In addition, the reduced magnetic meridional neutral wind velocity leads to lower F-region peak altitudes in the summer hemisphere and a higher F-region peak altitudes in the winter hemisphere. The changes in the summer hemisphere results in decreased values for the F-region peak plasma concentration and for the plasma concentration at $800 \mathrm{~km}$ altitude. In the winter hemisphere, the higher F-region peak altitude leads to increased plasma concentrations in the F-region and increased concentrations at $800 \mathrm{~km}$ altitude.

The modelled $\mathrm{O}^{+}$and electron temperatures, and electron concentrations, shown in Fig. 5 have been obtained from calculations with magnetic declination angle $-15^{\circ}$, which include the vertical $\mathbf{E} \times \mathbf{B}$ plasma drift velocity pattern described (see Fig. 4), and those obtained from calculations in which the drift is taken to be zero. A comparison of the temperature profiles shows that $\mathbf{E} \times \mathbf{B}$ drift has little effect on the latitudinal distributions of the temperatures at $800 \mathrm{~km}$ altitude and $21.00 \mathrm{LT}$. This result is in agreement with the results of previous studies (e.g., Bailey et al., 1973). There are, however, major differences in the electron concentration profiles at latitudes around the magnetic equator $\left( \pm 20^{\circ}\right)$. Within this region, the downward vertical $\mathbf{E} \times \mathbf{B}$ plasma drift leads to electron concentrations that vary little with latitude and which are much higher than those outside this region. This increase in electron concentration is a consequence of the upward daytime $\mathbf{E} \times \mathbf{B}$ plasma drift transporting high-density plasma from lower altitudes (Bailey et al., 1997). 
The profiles displayed in Figs. 6 and 7 show, respectively, latitude and altitude variations of the characteristic features of the troughs and crests at $21.00 \mathrm{LT}$. These profiles have been obtained by subtraction of the temperature profiles obtained from model calculations that exclude the $p \operatorname{div} \mathbf{v}$ term in the ion and electron energy equations (set B calculations) from those that include the term (set A calculations). The latitudinal profiles displayed in Fig. 6 are for $800 \mathrm{~km}$ altitude. The altitude profiles displayed in Fig. 7 are for latitudes $-6^{\circ}$ and $16^{\circ}$. These latitudes are close to the trough centres and crest peaks, respectively.

As these figures show, and as discussed already, the greatest trough depths and crest values occur when the magnetic declination angle is $15^{\circ}$ and smallest when it is $-15^{\circ}$. Both the latitude and altitude of the $\mathrm{O}^{+}$and electron temperature crest peaks increase with increasing magnetic meridional wind. The $\mathrm{O}^{+}$crest peak can exceed that of the electrons by more than a factor 2 . The much smaller latitudinal variation in the electron
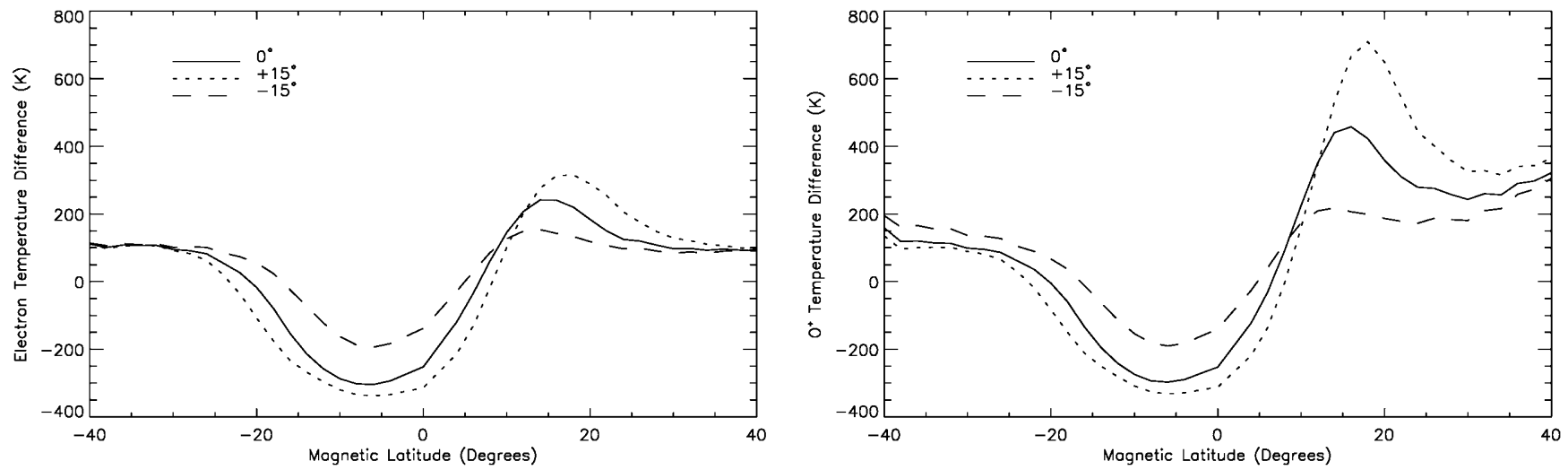

Fig. 6. Latitudinal profiles at $800 \mathrm{~km}$ altitude and $21.00 \mathrm{LT}$ of the modelled $\mathrm{O}^{+}$and electron temperature differences obtained from calculations with magnetic declination angles $0^{\circ}, 15^{\circ}$, and $-15^{\circ}$
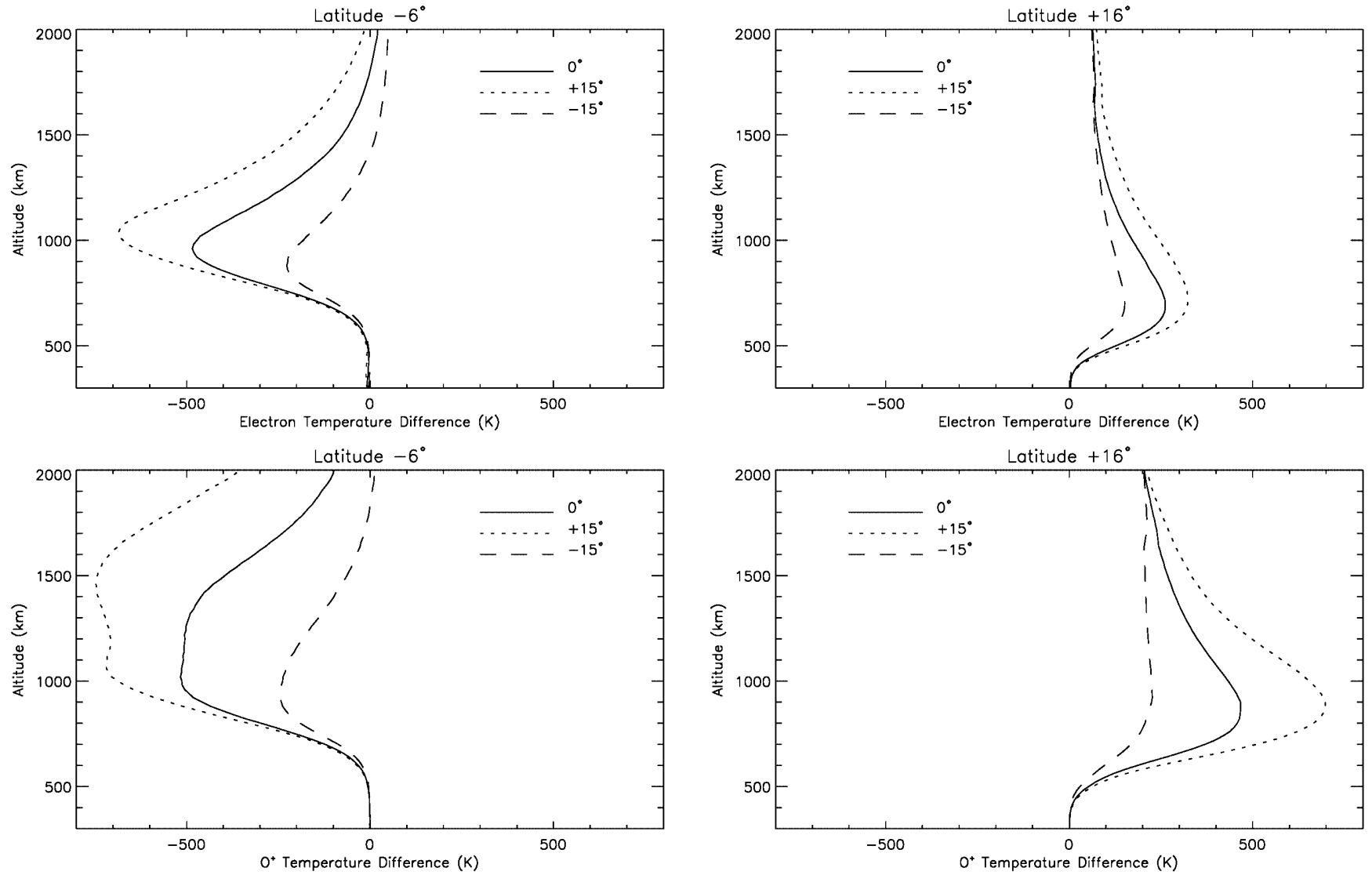

Fig. 7. Altitude profiles at $21.00 \mathrm{LT}$ of the modelled $\mathrm{O}^{+}$and electron temperature differences at latitudes $-6^{\circ}$ and $16^{\circ}$ obtained from calculations with magnetic declination angles $0^{\circ}, 15^{\circ}$, and $-15^{\circ}$ 
temperature is a result of the major role played by thermal conduction in the electron gas; thermal conduction in the ion gas is almost negligible. At the latitudes of the trough, there is little difference in the modelled $\mathrm{O}^{+}$and electron temperatures at $800 \mathrm{~km}$ altitude due to the strong thermal coupling of the $\mathrm{O}^{+}$ and electron gases arising from the high plasma concentrations. With increasing altitude, the weaker thermal coupling leads to increased differences in the $\mathrm{O}^{+}$ and electron temperatures. At the higher altitudes, the increasing influence of the $\mathrm{H}^{+}$ion leads to decreases in the differences between the $\mathrm{O}^{+}$and electron temperatures. The greatest trough depth occurs at around $1000 \mathrm{~km}$ altitude. The trough depth of the $\mathrm{O}^{+}$temperature has a broad maximum between about 1000 and $1500 \mathrm{~km}$ altitude. The greater the magnetic meridional wind, the broader the altitude extent of the trough maximum.

Figure 7 shows clearly that the troughs and crests only occur within an altitude range. For adiabatic cooling/heating to be sufficient to produce troughs/ crests, both the plasma scale height and the coupling to the neutral gases have to be low. These conditions are met at altitudes below the $\mathrm{O}^{+} / \mathrm{H}^{+}$transition height and above about $600 \mathrm{~km}$ altitude (see also Bailey and Heelis, 1980). The temperature differences that occur at the
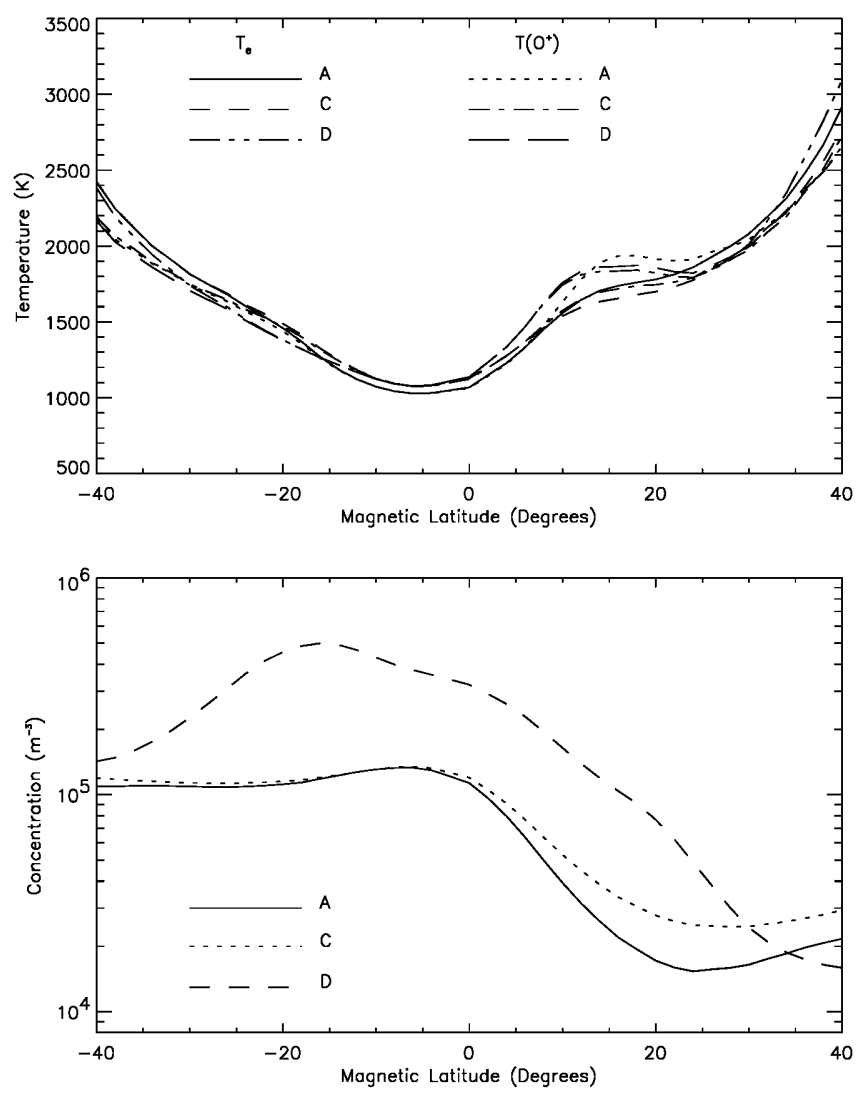

Fig. 8. Latitudinal profiles at $800 \mathrm{~km}$ altitude and $21.00 \mathrm{LT}$ of the modelled $\mathrm{O}^{+}$and electron temperatures, electron concentration, $\mathrm{O}^{+}$ field-aligned velocity, and magnetic meridional wind, obtained from calculations with magnetic declination angle $0^{\circ}$. The curves labelled $A$ have been obtained from model calculations that use the magnetic higher latitudes and altitudes of Figs. 6 and 7, respectively, arise from the role played by the $p \operatorname{div} \mathbf{v}$ term and plasma transport in the energy balance along the higher apex-altitude field lines. They do not indicate the occurrence of temperature crests.

The characteristic features of the troughs and crests are not only determined by the magnitude of the magnetic meridional wind velocity but, also, by its latitudinal variation. This is demonstrated by the results displayed in Fig. 8. In this figure are displayed the modelled $\mathrm{O}^{+}$and electron temperatures, electron concentrations, and $\mathrm{O}^{+}$field-aligned velocities obtained from calculations (set A) with magnetic declination angle $0^{\circ}$ and those obtained from model calculations in which the magnitude of the neutral wind has not been increased by the factor 2 (set C) and with no latitudinal displacement in the geographic meridional wind (set D). The wind patterns for these calculations are also displayed in Fig. 8; the wind pattern described by the solid curve is the same as that described by the solid curve of Fig. 2. For the set $\mathrm{C}$ calculations, the interhemispheric transport generated by the magnetic meridional wind is insufficient to induce significant crests in the plasma temperature in the winter hemisphere. The greater $\mathrm{O}^{+}$and electron concentrations in the winter hemisphere lead to reduced differences in the $\mathrm{O}^{+}$and
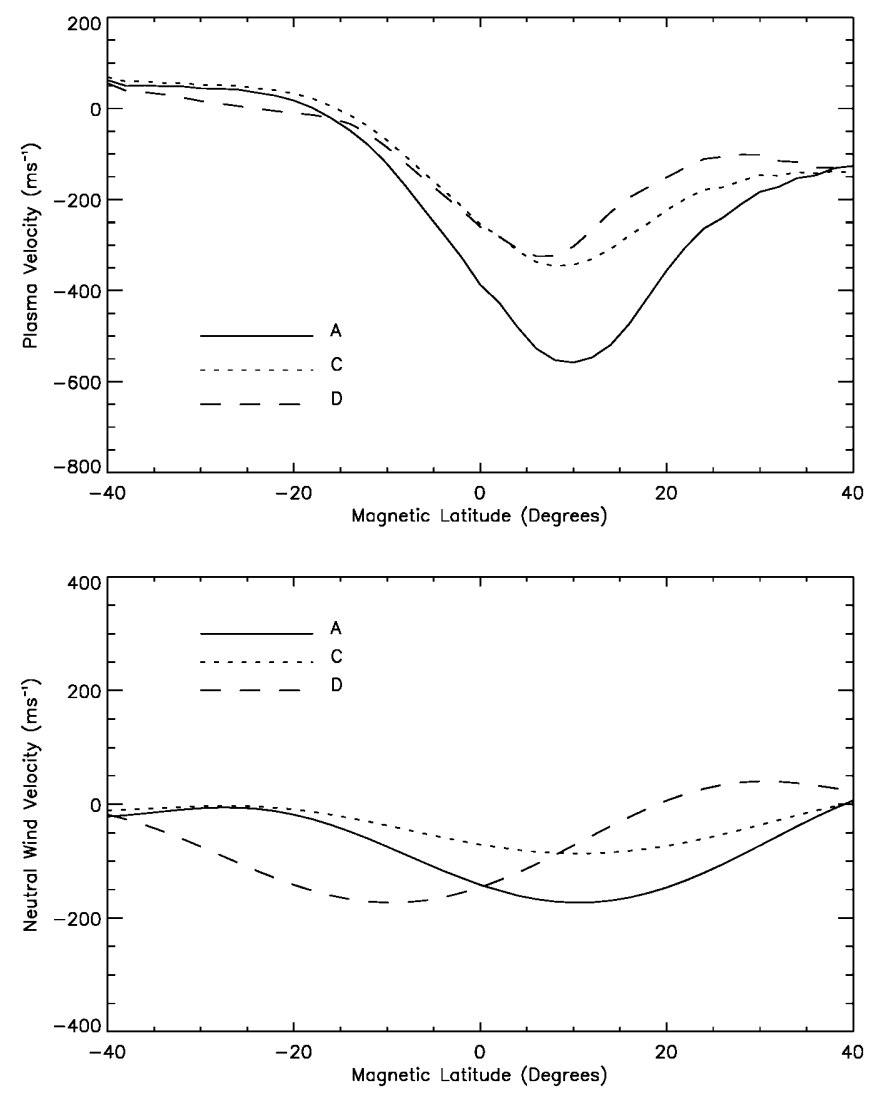

meridional wind pattern displayed in Fig. 2, the curves labelled $C$ from model calculations in which the magnitude of the neutral wind has not been increased by the factor 2, and the curves labelled $D$ from model calculations in which there is no latitudinal displacement in the geographic meridional wind 
electron temperatures. When there is no latitudinal displacement in the magnetic meridional wind the greater equatorward-directed wind raises the $\mathrm{F}$ region in the summer hemisphere, which leads to increased $\mathrm{O}^{+}$ and electron concentrations at $800 \mathrm{~km}$ altitude. Although the $\mathrm{F}$ region in the winter hemisphere is lower in altitude compared to that obtained from calculations with no displacement in the magnetic meridional wind, the interhemispheric flow of plasma from the summer hemisphere keeps the $\mathrm{O}^{+}$and electron concentrations at $800 \mathrm{~km}$ altitude high. As a consequence, the $\mathrm{O}^{+}$and electron field-aligned velocities at $800 \mathrm{~km}$ altitude are reduced in magnitude. This leads to reduced crests in the $\mathrm{O}^{+}$temperature. The crest in the $\mathrm{O}^{+}$temperaure is, as expected, slightly more prominent than in the electron temperature.

The characteristic features of the troughs and crests in the latitudinal distributions of the ion and electron temperatures are determined by the contributions made by the individual cooling and heating processes to the total energy balance. Shown in Fig. 9 are the values of the individual terms of the $\mathrm{O}^{+}$and electron energy equations at $800 \mathrm{~km}$ altitude and $21.00 \mathrm{LT}$. The values shown in this figure have been determined from calculations which include the $p \operatorname{div} \mathbf{v}$ term in the energy equation, do not include the vertical $\mathbf{E} \times \mathbf{B}$ plasma drift, and have magnetic declination angle $0^{\circ}$, i.e., the set $\mathrm{A}$ values displayed in the left-hand panel of Fig. 3. The values of the terms are given with their signs arranged so that at any point their algebraic sum is zero, i.e. the terms on the left-hand side of Eq. 1 have been moved to the right-hand side.

In the electron gas, the $p$ div $\mathbf{v}$ term (labelled PDIV in Fig. 9) is the principal heat sink in the summer hemisphere and the principal heat source in the winter hemisphere. In the summer hemisphere, the $p \operatorname{div} \mathbf{v}$ term is balanced, principally, by heating from the photoelectrons [labelled $\mathrm{Q}(\mathrm{E})$ in Fig. 9] and thermal conduction (labelled CON in Fig. 9). In the winter hemisphere, the ion gases make important contributions to the heating. This heating [labelled Q(E-I) in Fig. 9], combined with that from the $p$ divv term is balanced by thermal conduction. The $p \operatorname{div} \mathbf{v}$ term in the $\mathrm{O}^{+}$gas also acts as a heat sink in the summer hemisphere and a heat source in the winter hemisphere. However, thermal conduction in the ion gases is small and plays a minor role in the energy balance of the ion gases. For $\mathrm{O}^{+}$, the $p \operatorname{div} \mathbf{v}$ term in the summer hemisphere is balanced principally by its thermal coupling with the neutrals [labelled $\mathrm{Q}\left(\mathrm{O}^{+}-\mathrm{N}\right)$ in Fig. 9] and electrons [labelled $\mathrm{Q}\left(\mathrm{O}^{+}-\mathrm{E}\right)$ in Fig. 9]. In the winter hemisphere, the $p \operatorname{div} \mathbf{v}$ term is balanced by the heat lost to the electrons, $\mathrm{H}^{+}$ions, and neutral gases. For the $\mathrm{H}^{+}$gas (figure not shown), the $p \operatorname{div} \mathbf{v}$ term is small. At trough latitudes, the principal source of heating are the electrons and this is balanced, principally, by cooling to the $\mathrm{O}^{+}$ions. At latitudes around the temperature crests, the roles are reversed with the electron and $\mathrm{O}^{+}$gases acting as heat sinks and heat sources, respectively.

A comparison of the electron concentration profiles obtained from the model calculations that include and exclude the $p \operatorname{div} \mathbf{v}$ term in the ion and electron energy equations show significant differences (see Fig. 3). Within the trough region, the calculations that include the $p \operatorname{div} \mathbf{v}$ term (set $\mathrm{A}$ ) give electron concentrations that are higher than those that exclude the term (set B) even though the plasma temperatures are lower. Around the crests, the model calculations give lower electron concentrations when the $p \operatorname{div} \mathbf{v}$ term is included in the calculations even though the plasma temperatures are higher. These unexpected behaviours can be explained by considering the altitude profiles of the $\mathrm{O}^{+}$and $\mathrm{H}^{+}$ ions. Shown in Fig. 10 are the altitude profiles of the $\mathrm{O}^{+}$ and $\mathrm{H}^{+}$concentrations at $-16^{\circ}$ and $16^{\circ}$. These latitudes are representative of the latitudes where the greatest differences in the two sets of calculations occur.

At altitudes below about $800 \mathrm{~km}$, the distribution of $\mathrm{H}^{+}$is largely controlled by chemical production and loss through the reactions

$$
\begin{aligned}
& \mathrm{O}^{+}+\mathrm{H} \rightarrow \mathrm{H}^{+}+\mathrm{O} \\
& \mathrm{H}^{+}+\mathrm{O} \rightarrow \mathrm{O}^{+}+\mathrm{H}
\end{aligned}
$$

which have rate coefficients proportional to $T_{n}^{0.5}$ and $T^{0.5}\left(\mathrm{H}^{+}\right)$, respectively, where $T_{n}$ denotes the neutral gas temperature and $T\left(\mathrm{H}^{+}\right)$the temperature of the $\mathrm{H}^{+}$ions.
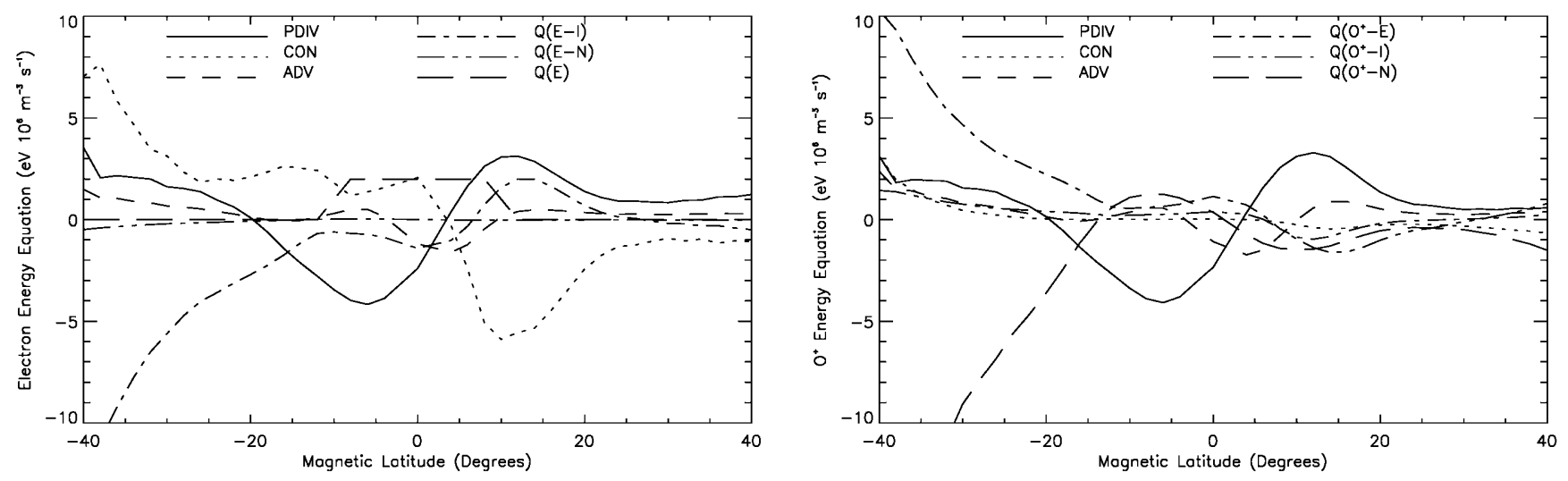

Fig. 9. Latitudinal profiles at $800 \mathrm{~km}$ altitude and $21.00 \mathrm{LT}$ of the values of the individual terms of the electron and $\mathrm{O}^{+}$energy equations obtained from calculations set A with magnetic declination angle $0^{\circ}$. The signs of the terms have been arranged so that their algebraic sum is zero 

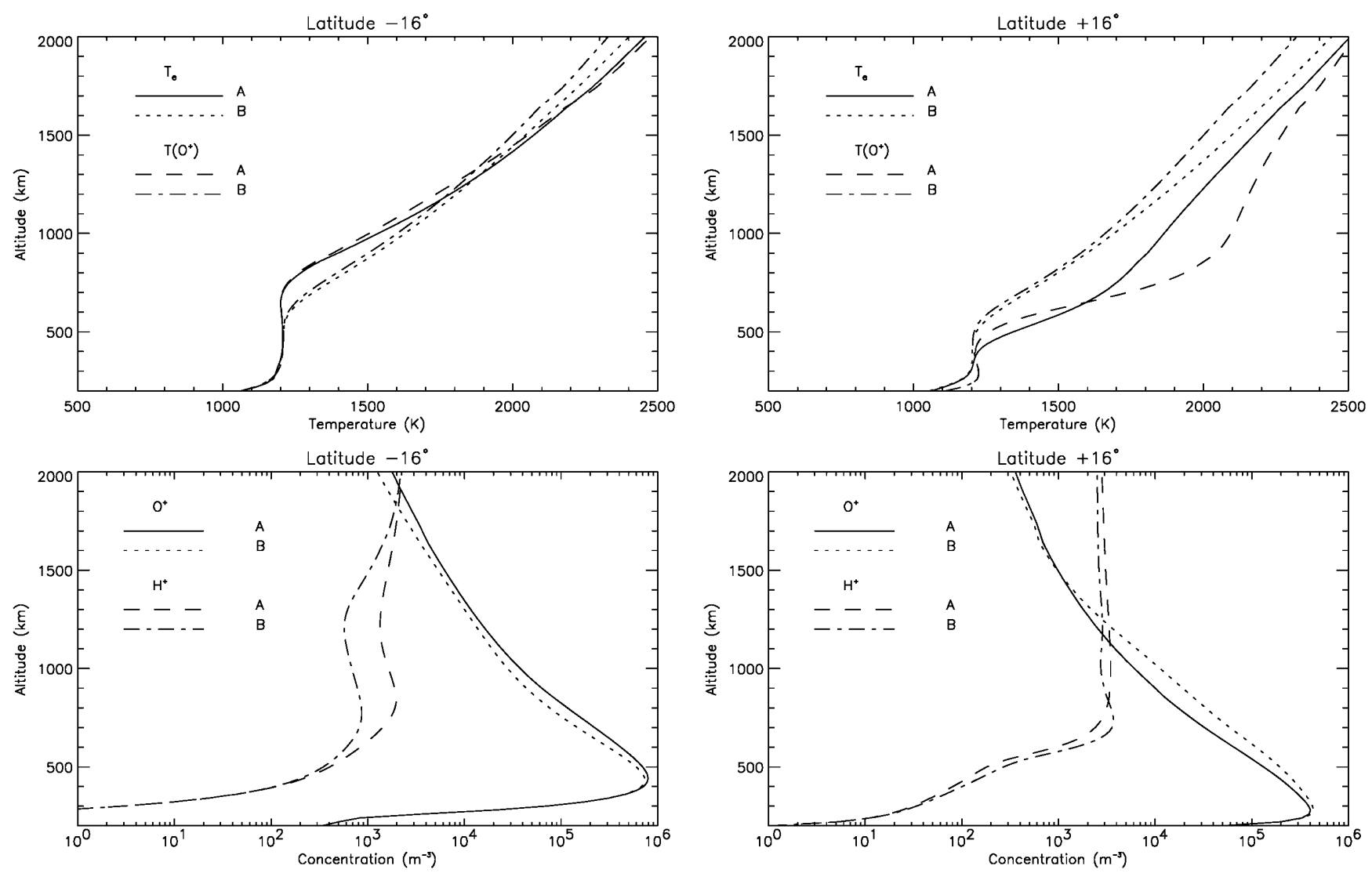

Fig. 10. Altitude profiles at $21.00 \mathrm{LT}$ of the modelled $\mathrm{O}^{+}$and electron temperatures, and $\mathrm{O}^{+}$and $\mathrm{H}^{+}$concentrations, at latitudes $-16^{\circ}$ and $16^{\circ}$ obtained from calculations set $\mathrm{A}$ and set $\mathrm{B}$ with magnetic declination angle $0^{\circ}$

It should be borne in mind that, for the modelled values considered here, the $\mathrm{H}^{+}$temperature lies between the $\mathrm{O}^{+}$ and electron temperatures. Thus, at the latitudes of the trough, the lower $\mathrm{H}^{+}$temperatures that occur below $800 \mathrm{~km}$ altitude reduces the chemical loss of $\mathrm{H}^{+}$ (reaction 8) at those altitudes which, in turn, leads to increases in the $\mathrm{H}^{+}$concentration (see Fig. 10). The downward diffusion of $\mathrm{O}^{+}$is, therefore, reduced and the $\mathrm{O}^{+}$concentration increased. At the latitudes around the crests, the higher $\mathrm{H}^{+}$temperatures increase the chemical loss of $\mathrm{H}^{+}$which, in turn, leads to reduced $\mathrm{H}^{+}$ concentrations at altitudes below about $800 \mathrm{~km}$. At these altitudes, the $\mathrm{O}^{+}$diffusion coefficient is increased and this leads to reduced $\mathrm{O}^{+}$concentrations.

\section{Conclusions}

Observations from the DMSP F10 satellite at 21.00 LT and $800 \mathrm{~km}$ altitude show troughs and crests in the latitudinal profiles of the ion and electron temperatures. The longitudinal variations in the averaged observed latitudinal profiles for January 1991, when $F 10.7$ was around 220, have been reproduced by the values modelled by SUPIM (Sheffield University Plasmasphere Ionosphere Model). It has been verified that the troughs/crests are due to adiabatic cooling/heating of the plasma as the plasma flows along magnetic field lines from the summer hemisphere to the winter hemisphere.
The modelled values confirm that the plasma fieldaligned velocities needed to produce the troughs and crests can be induced by neutral winds. At $800 \mathrm{~km}$ altitude, F-region magnetic meridional winds of about $200 \mathrm{~ms}^{-1}$ induce $\mathrm{O}^{+}$field-aligned velocities approaching $600 \mathrm{~ms}^{-1}$. The longitudinal variations in the characteristic features of the troughs and crests are shown to be due to the longitudinal variations in the magnetic meridional wind. This wind component is strongly dependent upon the geographic meridional wind, with the geographic zonal wind playing a significant role at longitudes where the magnetic declination angle is large. At longitudes where the magnetic declination angle is positive the eastward geographic zonal wind combines with the northward (summer hemisphere to winter hemisphere) geographic meridional wind to enhance the northward magnetic meridional wind. This leads to deeper troughs and enhanced crests. At longitudes where the magnetic declination angle is negative, the eastward geographic zonal wind opposes the northward geographic meridional wind and the trough depth and crest values are reduced. Consideration of the individual terms of the ion and electron energy equations shows that the characteristic features of the troughs and crests depend, in a complicated manner, on the field-aligned flow of plasma, thermal conduction, and inter-gas heat transfer. The high/low electron concentration values that occur at the latitudes of the temperature troughs/ crests result from the reduced/increased chemical loss of 
$\mathrm{H}^{+}$and the subsequent change to the $\mathrm{O}^{+}$diffusion coefficient and downward diffusion of the $\mathrm{O}^{+}$ion.

Acknowledgements. This work was supported by the Particle Physics and Astronomy Research Council (PPARC) under grant PPA/G/O/1997/00691 to the University of Sheffield and by the National Science Foundation grant ATM-9615064 and NASA grant NAG5-4456 to the University of Texas. One of us (MD) was supported by a PPARC studentship.

Topical Editor M. Lester thanks K. I. Oyama and H. Rishbeth for their help in evaluating this paper.

\section{References}

Bailey, G. J., and N. Balan, A low-latitude ionosphere-plasmasphere model, in STEP handbook on ionospheric models Ed. R.W. Schunk, Utah State University, 173-206, 1996.

Bailey, G. J., and R. A. Heelis, Ion temperature troughs induced by a meridional neutral air wind in the nighttime equatorial topside ionosphere, Planet. Space Sci., 28, 895-906, 1980.

Bailey, G. J., and R. Sellek, A mathematical model of the Earth's plasmasphere and its application in a study of $\mathrm{He}^{+}$, Ann. Geophysicae, 8, 171-190, 1990.

Bailey, G. J., N. Balan, and Y. Z. Su, The Sheffield University plasmasphere ionosphere model - a review, J. Atmos. Sol-Terr. Phys., 59, 1541-1552, 1997.

Bailey, G. J., R. J. Moffett, W. B. Hanson, and S. Sanatani, Effects of interhemispheric transport on plasma temperatures at low latitudes, J. Geophys. Res., 78, 5597-5610, 1973.

Bailey, G. J., R. Sellek, and Y. Rippeth, A modelling study of the equatorial topside ionosphere, Ann. Geophysicae, 11, 263-272, 1993.

Balan, N., K.-I. Oyama, G. J. Bailey, and T. Abe, Plasmasphere electron temperature profiles and the effects of photoelectron trapping and an equatorial high-altitude heat source, J. Geophys. Res., 101, 21 689-21 696, 1996.

Balan, N., K.-I. Oyama, G. J. Bailey, S. Watanabe, S. Fukao, and M. A. Abdu, A plasma temperature anomaly in the equatorial topside ionosphere, J. Geophys. Res., 102, 7485-7492, 1997.

Blum, P. W., and I. Harris, Full non-linear treatment of the global thermospheric wind system - II. Results and comparison with observations, J. Atmos. Terr. Phys., 37, 213-235, 1975.

Bühler, P., Radiation belts, Proc. ESA Workshop on Space Weather, ESTEC, Noordwijk, The Netherlands, 91-98, 1998.

Chandler, M. O., J. J. Ponthieu, T. E. Cravens, A. F. Nagy, and P. G. Richards, Model calculations of minor ion populations in the plasmasphere, J. Geophys. Res., 92, 5885-5895, 1987.
Hanson, W. B., A. F. Nagy, and R. J. Moffett, Ogo 6 measurements of supercooled plasma in the equatorial exosphere, J. Geophys. Res., 78, 751-756, 1973.

Hedin, A. E., MSIS-86 thermospheric model, J. Geophys. Res., 92, 4649-4662, 1987.

Hedin, A. E., M. A. Biondi, R. G. Burnside, G. Hernandez, R. M. Johnson, T. L. Killeen, C. Mazaudier, J. W. Meriwether, J. E. Salah, R. J. Sica, R. W. Smith, N. W. Spencer, V. B. Wickwar, and T. S. Virdi, Revised global model of thermosphere winds using satellite and ground-based observations, J. Geophys. Res., 96, 7657-7688, 1991.

Heelis, R. A., G. J. Bailey, and W. B. Hanson, Ion temperature troughs and interhemisperic transport observed in the equatorial ionosphere, J. Geophys. Res., 83, 3683-3689, 1978.

Oyama, K.-I., M. A. Abdu, N. Balan, G. J. Bailey, S. Watanabe, T. Takahashi, E. R. de Paula, I. S. Batista, F. Isoda, and H. Oya, High electron temperature associated with the prereversal enhancement in the equatorial ionosphere, J. Geophys. Res., 102, 417-424, 1997.

Richards, P. G., and D. G. Torr, Ratios of photoelectron to EUV ionization rates for aeronomic studies, J. Geophys. Res., 93, 4060-4066, 1988.

Richards, P. G., J. A. Fennelly, and D. G. Torr, EUVAC: A solar EUV flux model for aeronomic calculations, J. Geophys. Res., 99, 8981-8992, 1994.

Rishbeth, H., Thermospheric winds and the F region: a review, J. Atmos. Terr. Phys., 34, 1-47, 1972.

Rishbeth, H., T. E. Van Zandt, and W. B. Hanson, Ion temperature troughs in the equatorial topside ionosphere, Planet. Space Sci., 25, 629-642, 1977.

Scherliess, L., and B. J. Fejer, Radar and satellite global equatorial F region vertical drift model, J. Geophys. Res., 104, 6829-6842, 1999.

Stening, R. J., Modelling the low-latitude F region, J. Atmos. Terr. Phys., 54, 1387-1412, 1992.

Su, Y. Z., K.-I. Oyama, G. J. Bailey, T. Takahashi, and S. Watanabe, Comparison of satellite electron density and temperature measurements at low latitudes with a plasmasphere-ionosphere model, J. Geophys. Res., 100, 14 591-14 604, 1995.

Venkatraman, S., and R. A. Heelis, Longitudinal and seasonal variations in nighttime plasma temperatures in the equatorial topside ionosphere during solar maximum, J. Geophys. Res., 104, 2603-2611, 1999a.

Venkatraman, S., and R. A. Heelis, Effects of solar activity variations on adiabatic heating and cooling effects in the nighttime equatorial topside ionosphere, J. Geophys. Res., 104, 17 117-17 126, 1999b. 